\title{
Mechanisms of the Aggregation of Graphene Oxide at high pH: Roles of Oxidation Debris and Metal Adsorption
}

Huan Tang a,b*, Shuyan Zhang a,b, Tinglin Huang ${ }^{a, b^{*}}$, Jianfeng Zhang a,b, and Baoshan Xing ${ }^{\mathrm{c}}$

${ }^{a}$ Key Laboratory of Northwest Water Resource, Environment and Ecology, MOE, Xi'an

University of Architecture and Technology, Xi'an, 710055, China

${ }^{\mathrm{b}}$ Shaanxi Key Laboratory of Environmental Engineering, Xi'an University of Architecture and Technology, Xi'an, 710055, China

'Stockbridge School of Agriculture, University of Massachusetts, Amherst, MA, 01003, USA

Number of Pages: 28

Number of Figures: 18

Number of Tables: 1 


\section{Preparation of synthetic freshwater}

Table S1. The chemical composition of synthetic freshwater ${ }^{1}$

\begin{tabular}{ccccc|ccc}
\hline \multirow{2}{*}{ Water Type } & \multicolumn{3}{c|}{ Reagent Added(mg/L) } & \multicolumn{2}{c}{ Approximate Final Water Quality } \\
\cline { 2 - 7 } & $\mathrm{NaHCO}_{3}$ & $\mathrm{CaSO}_{4} \cdot \mathrm{H}_{2} \mathrm{O}$ & $\mathrm{MgSO}_{4}$ & $\mathrm{KCl}$ & $\mathrm{pH}$ & Hardness & Alkalinity \\
\hline Soft & 48.0 & 30.0 & 30.0 & 2.0 & $7.2-7.6$ & $40-48$ & $30-35$ \\
Moderately Hard & 96.0 & 120.0 & 60.0 & 4.0 & $7.4-7.8$ & $80-100$ & $57-64$ \\
Hard & 192.0 & 240.0 & 120.0 & 8.0 & $7.8-8.0$ & $160-180$ & $110-120$ \\
\hline
\end{tabular}

\section{Standard preparation method}

To prepare $20 \mathrm{~L}$ of synthetic, moderately hard, reconstituted water, use the reagent grade chemicals in Table S1. as follows:

1. Place 19 L of MILLI-Q water in a properly cleaned plastic carboy.

2. Add $1.20 \mathrm{~g}$ of $\mathrm{MgSO} 4,1.92 \mathrm{~g} \mathrm{NaHCO}_{3}$, and $0.080 \mathrm{~g} \mathrm{KCl}$ to the carboy.

3. Aerate overnight.

4. Add $1.20 \mathrm{~g}$ of $\mathrm{CaSO}_{4} \cdot 2 \mathrm{H}_{2} \mathrm{O}$ to $1 \mathrm{~L}$ of MILLI-Q water in a separate flask. Stir on magnetic stirrer until calcium sulfate is dissolved, add to the $19 \mathrm{~L}$ above, and mix well.

6. Aerate the combined solution vigorously for an additional $24 \mathrm{~h}$ to dissolve the added chemicals.

7. The measured $\mathrm{pH}$, hardness, etc., are listed in Table S1. 


\section{Adsorption of metal cations on GO}

All adsorption experiments were carried out triplicate using 50mg/L GO mixed with different concentrations of metal ions corresponding to the aggregation experiment at room temperature of $300 \mathrm{~K}$ in a conical flask. The supernatant was taken through $0.22 \mu \mathrm{m}$ nanofiltration membrane to ensure that only metal ions remained. Control experiment indicated that the cations showed no affinity to the $0.22 \mu \mathrm{m}$ filter. The concentration of metal ions was determined by Atomic Absorption Spectrometry (AAS, Thermo Scientific iCE 3300) to get the adsorption amount of metal ions on $\mathrm{GO}$ as a function of time and $\mathrm{pH}$. The detection limits and detection wavelengths of AAS are shown in Table S2.

Table S2. Details for the AAS measurement.

\begin{tabular}{cccc}
\hline Metal ion species & $\begin{array}{c}\text { Detection } \\
\text { wavelength(nm) }\end{array}$ & $\begin{array}{c}\text { Minimum detectable } \\
\text { concentration(mg/L) }\end{array}$ & $\begin{array}{c}\text { Suitable concentration } \\
\text { range }(\mathrm{mg} / \mathrm{L})\end{array}$ \\
\hline $\mathrm{Ca}^{2+}$ & 422.7 & 0.02 & $0.1 \sim 6.0$ \\
$\mathrm{Mg}^{2+}$ & 285.2 & 0.002 & $0.01 \sim 6.0$ \\
$\mathrm{~K}^{+}$ & 766.5 & 0.03 & $0.05 \sim 4.0$ \\
& 404.4 & 0.4 & $1 \sim 300$ \\
$\mathrm{Na}^{+}$ & 589.0 & 0.01 & $0.05 \sim 2.0$ \\
& 330.3 & 0.1 & $0.5 \sim 200$ \\
\hline
\end{tabular}




\section{GO Aggregation Kinetics ${ }^{2,3}$}

The initial aggregation rate constant $\left(\mathrm{k}_{\mathrm{a}}\right)$ is proportional to the initial growth of $\mathrm{D}_{\mathrm{h}}$ as a function of $\mathrm{t}$, but inversely proportional to the initial primary particle concentration $\left(\mathrm{N}_{0}\right)$

$$
k_{\mathrm{a}} \propto \frac{1}{N_{0}}\left(\frac{d D_{\mathrm{h}}(t)}{d t}\right)_{t \rightarrow 0}
$$

The attachment efficiency $(\alpha)$, which is also known as the inverse stability ratio( $1 / \mathrm{W})$, represents the ratio of the aggregation rate in the presence of an energy barrier to the aggregation rate in the absence of an energy barrier. Therefore, $\alpha$ can be determined by normalizing the initial aggregation rate constant to the initial aggregation rate $\left(\mathrm{k}_{\mathrm{a}}, \mathrm{f}_{\mathrm{av}}\right)$ under the favorable aggregation (or diffusion-controlled) condition.

$$
\alpha=\frac{1}{W}=\frac{k_{\mathrm{a}}}{k_{\mathrm{a}, \mathrm{fav}}}=\frac{\frac{1}{N_{0}}\left(\frac{d D_{\mathrm{h}}(t)}{d t}\right)_{t \rightarrow 0}}{\frac{1}{\left(N_{0}\right)_{\mathrm{fav}}}\left(\frac{d D_{\mathrm{h}}(t)}{d t}\right)_{t \rightarrow 0, \mathrm{fav}}}=\frac{\left(\frac{d D_{\mathrm{h}}(t)}{d t}\right)_{t \rightarrow 0}}{\left(\frac{d D_{\mathrm{h}}(t)}{d t}\right)_{t \rightarrow 0, \mathrm{fav}}}
$$

where the subscript "fav" denotes favorable aggregation conditions, the hydrodynamic radius increases from $\mathrm{D}_{\mathrm{h} 0}$ to $1.5 \mathrm{D}_{\mathrm{h} 0}$ at the fastest aggregation rate. The $\mathrm{pH}$ value of a certain kind of water type as the horizontal axis and the attachment efficiency as the vertical axis. 


\section{Characterization of GO}

Thermal properties of the GO samples were characterized by Simultaneous Thermal Analysis (DSC-TGA, SDT Q600), and all of the measurements were carried out under nitrogen gas (100.0 $\mathrm{ml} / \mathrm{min}$ ) over a temperature range of 28 to $800{ }^{\circ} \mathrm{C}$ with a ramp rate of $5{ }^{\circ} \mathrm{C} / \mathrm{min}^{4}, 5$. Fourier transform infrared spectroscopy (FTIR) and X-ray photoelectron spectroscopy (XPS) was used to determine the surface functionalities of GO. The area under peaks from the XPS spectra was used for quantifying the relative concentration of functional groups. Three-dimensional fluorescence spectra of GO were recorded at ambient temperature with a fluorescence spectrometer (F-7000 Hitachi), at emission wavelength 350 to $550 \mathrm{~nm}$ and excitation wavelength 250 to $450 \mathrm{~nm}^{6,7}$. The photomultiplier tube voltage was $700 \mathrm{~V}$, scan speed was $12000 \mathrm{~nm} / \mathrm{min}$, and the slit widths for excitation and emission were $2.5 \mathrm{~nm}$ and $5.0 \mathrm{~nm}$, respectively. The surface morphologies of GO and ODs were examined using a Bruker BioScope Atomic Force Microscope (AFM). To explore the bridging effect of ODs at high $\mathrm{pH}, \mathrm{GO}$ suspension $(20 \mathrm{mg} / \mathrm{L})$ at 14 and $\mathrm{pH} 12$ with $0.50 \mathrm{mM}$

$\mathrm{Ca}^{2+}$ were used. Before the measurements, the suspensions were shaken for $10 \mathrm{~min} .3 \mu \mathrm{L}$ of the mixtures were dripped onto the mica plates and dried for AFM measurements, and images were taken at several random locations across the sample. 


\section{Amount of deprotonated functional groups and dissociation constant}

Concentrations of the deprotonated groups present on GO at different $\mathrm{pH}$ were determined by acid-base titration $^{8}$. $0.05 \mathrm{~g}$ of GO was added in a conical flask containing $20 \mathrm{ml}$ of $0.1 \mathrm{M} \mathrm{NaOH}$ solution at room temperature of $300 \mathrm{~K}$. The titrations were carried out with a $0.1 \mathrm{~mol} / \mathrm{L} \mathrm{HCl}$ solution added in incremental steps of $0.05,0.1,0.2 \mathrm{~mL}$ and the equilibrium $\mathrm{pH}$ at each step was recorded (Figure S1, red curve). To determine the amount of deprotonated functional groups, the titration was repeated with the same volume of $\mathrm{NaOH}$ but without addition of GO (Figure S1, black curve). The difference in the volumes of $\mathrm{HCl}$ in the two titration curves for the same value of $\mathrm{pH}$, indicated as $\Delta_{\mathrm{HCl}}$ in Figure $4 \mathrm{~b}$, gives the concentration of the ionized groups per gm of GO at that $\mathrm{pH}$. The amount of the ionized groups per gm as a function of $\mathrm{pH}$ was named the sodium binding isotherm. By further differentiating the sodium binding isotherm, the $\mathrm{pKa}$ values of the different ionizable functionalities present on GO can be obtained ${ }^{8}$.

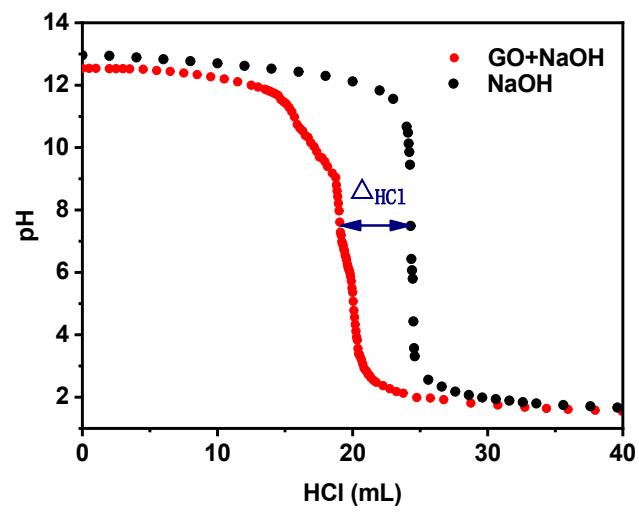

Figure S1. pH titration curve of GO (red curve). The black curve is the blank titration, $\triangle_{\mathrm{HCl}}$ is the difference in the volume of $\mathrm{HCl}$ added in the two titrations at the same $\mathrm{pH}$. 


\section{Preparations of FG and OD}

The FG and OD were prepared by GO alkaline washing with $0.1 \mathrm{M}$ sodium hydroxide. According to the results of three-dimensional fluorescence, the alkaline washing treatment time was selected as $5 \mathrm{~min}$, at which time OD had fallen off and the reduction effect could be avoided. Immediately, the black mixture was centrifuged at $12,000 \mathrm{rpm}$ for $10 \mathrm{~min}$ to obtain a yellow-brown supernatant and a black sediment, then reprotonated with a $1.0 \mathrm{~mol} / \mathrm{L} \mathrm{HCl}$ solution. The former was processed using a cation exchange resin column and the latter using dialysis to remove excess sodium ions, and finally dried by lyophilization. Thus, brown powders (OD) and black powders (FG) were obtained. 


\section{DLVO and XDLVO theory calculation method}

According to the DLVO theory, the aggregation of GO is determined by electrostatic double layer (EDL) interactions and vdWs interactions, which can be calculated using the following equations 9 :

$G_{E D L}=2 \pi \varepsilon_{0} \varepsilon a \psi^{2} \operatorname{In}[1+\exp (-k h)]$

$G_{v d w}=-\frac{A_{101} \alpha}{12 h}\left[1+\frac{14 h}{\lambda}\right]^{-1}$

$\Delta G=G_{E D L}+G_{v d w}$

For the value of Hamaker constant, $\mathrm{A}_{101}, 6.26 \times 10^{-21} \mathrm{~J}$ was employed in this study ${ }^{10}$. Permittivity of free space $\left(\varepsilon_{0}\right)$ and the dielectric constant of water $(\varepsilon)$ were assumed to be $8.854 \times$ $10^{-12} \mathrm{C} / \mathrm{V} \cdot \mathrm{m}$ and 78.5 respectively ${ }^{11}$. Hydrodynamic size measured by DLS was used as particle size $(\alpha)$. A characteristic wavelength $(\lambda)$ of $100 \mathrm{~nm}$ was assumed ${ }^{12}$. In the place of surface potentials, zeta potential values $(\psi)$ were utilized. $k$ is the inverse of Debye length, which represents the thickness of the EDL. $h$ is the separation distance between GOs.

According to the XDLVO theory, ${ }^{13}$ the aggregation of GO (plate-plate system) is determined by EDL, vdWs, and Lewis acid-base (AB) interactions, which can be calculated using the following equations: ${ }^{14,15}$

$\Phi_{E D L}=\varepsilon_{0} \varepsilon_{\mathrm{w}} k \psi^{2}\left[\frac{1}{\sinh (k h)}+1-\operatorname{coth}(k h)\right]$

$\Phi_{v d W}=-\frac{A}{12 \pi h^{2}}$

$\Phi_{A B}=\Delta \mathrm{G}_{\mathrm{h}_{0}}^{\mathrm{AB}} \exp \left(\frac{h_{0}-h}{\lambda}\right)$

The total interaction energy $(\Phi)$ between GOs: $\Phi=\Phi_{E D L}+\Phi_{v d W}+\Phi_{A B}$

Permittivity of free space $\left(\varepsilon_{0}\right)$ and the dielectric constant of water $(\varepsilon)$ were $8.854 \times 10^{-12} \mathrm{C} / \mathrm{V} \cdot \mathrm{m}$ and $78.5 ;{ }^{3}$ zeta potential value was used in the place of surface potential $\psi ; h$ is the separation distance between GOs. $\lambda$ is the characteristic decay length of $\mathrm{AB}$ interactions in water, whose value is between 0.2 and $1.0 \mathrm{~nm}$, and a commonly used value of $\lambda$ for aqueous systems is $0.6 \mathrm{~nm} .{ }^{14,15} h_{0}$ represents the minimum equilibrium cut-off distance and is usually assigned a value of $0.157 \mathrm{~nm} .{ }^{16,17} k\left(\mathrm{~nm}^{-1}\right)$ is the inverse of Debye length and was calculated using the following equation: ${ }^{39}$

$$
k^{-1}=\sqrt{\frac{\varepsilon_{0} \varepsilon k_{B} T}{2 N_{A} e^{2} I_{s}}}
$$


$\mathrm{I}_{\mathrm{S}}=\frac{1}{2} \sum \mathrm{c}_{\mathrm{i}} \mathrm{Z}_{\mathrm{i}}$

where $k_{B}$ is Boltzmann's constant $\left(1.38064852 \times 10^{-23} \mathrm{~J} / \mathrm{K}\right){ }^{18}, T$ is absolute temperature (300K was employed in our study), $N_{A}$ is the Avogadro number $\left(6.022140857 \times 10^{23} \mathrm{~mol}^{-1}\right){ }^{19}, e$ is the electron charge $\left(1.6021766208 \times 10^{-19} \mathrm{C}\right){ }^{20} . I_{s}$ is ionic strength $(\mathrm{mol} / \mathrm{L}), \mathrm{c}_{\mathrm{i}}$ is concentration of molecules and $z_{i}$ is charge number of ion species $i^{21}$. Based on these values, the above equation can be transformed to:

$k \approx 3.28 \sqrt{\mathrm{I}_{\mathrm{s}}}$

$A$ represents the Hamaker constant and was calculated using: ${ }^{22}$

$A=24 \pi h_{0}^{2}\left(\sqrt{\gamma_{G O}^{L W}}-\sqrt{\gamma_{W}^{L W}}\right)^{2}$

$\Delta \mathrm{G}_{\mathrm{h}_{0}}^{\mathrm{AB}}$ is the acid-base free energy per unit area and was calculated using: ${ }^{22}$

$\Delta \mathrm{G}_{\mathrm{h}_{0}}^{\mathrm{AB}}=2\left[\sqrt{\gamma_{w}^{+}}\left(2 \sqrt{\gamma_{\overline{G O}}}-\sqrt{\gamma_{w}^{-}}\right)+\sqrt{\gamma_{w}^{-}}\left(2 \sqrt{\gamma_{G O}^{+}}-\sqrt{\gamma_{w}^{+}}\right)-2 \sqrt{\gamma_{\overline{G O}}^{-} \gamma_{G O}^{+}}\right]$

To obtain the value of $A$ and $\Delta \mathrm{G}_{\mathrm{AB}}$, the contact angles were measured. As the surface interfacial tension parameters of the selected probing liquids were known, the $\mathrm{vdWs}\left(\gamma_{G O}^{L W}\right)$, electron accepting $\left(\gamma_{G O}^{+}\right)$, and electron-donating $\left(\gamma_{\overline{G O}}\right)$ interfacial tension values for GO could be determined through the following equations: ${ }^{23}$

$\gamma_{i}^{L}(1+\cos \theta)=2 \sqrt{\gamma_{i}^{L W} \gamma_{G O}^{L W}}+2 \sqrt{\gamma_{i}^{+} \gamma_{\overline{G O}}^{-}}+2 \sqrt{\gamma_{i}^{-} \gamma_{G O}^{+}}$

where $i$ represent water, glycerol, and formamide, and the values of $\gamma_{i}^{*}$ are shown in Table S3.

Table S3. Surface Tension Components $\left(\mathrm{mJ} / \mathrm{m}^{2}\right)^{23,24}$

\begin{tabular}{ccccc}
\hline Probing Liquids & $\gamma_{i}^{L}$ & $\gamma_{i}^{L W}$ & $\gamma_{i}^{+}$ & $\gamma_{i}^{-}$ \\
\hline water & 72.8 & 21.8 & 25.5 & 25.5 \\
glycerol & 64.0 & 34.0 & 3.92 & 57.4 \\
formamide & 58.0 & 39.0 & 2.28 & 39.6 \\
\hline
\end{tabular}




\section{Molecular Dynamic Simulation}

The optimized potentials for liquid simulations-all atoms (OPLS-AA) force field ${ }^{25}$ implemented in the GROMACS 5.1 software package ${ }^{26}$ was used for all simulations. The L-J interactions were treated with a cutoff of $1 \mathrm{~nm}$. Short-range electrostatic interactions, up to a distance of $1 \mathrm{~nm}$ between the interacting atoms, were directly calculated using the Coulomb law. Long-range electrostatic interactions beyond $1 \mathrm{~nm}$ were accounted for employing the particle-mesh Ewald (PME) summation method. ${ }^{27}$ A simple-point charge (SPC) model ${ }^{28}$ was used for water molecules, which has been extensively tested in literature for interfacial studies. ${ }^{29}$ Bond lengths were constrained with LINCS $^{30}$ and water geometries were constrained with SETTLE ${ }^{31}$. Periodic boundary conditions were applied in all three directions.

For each system, static structure optimization was first performed to ensure that the maximum force is less than $1000.0 \mathrm{~kJ} /(\mathrm{mol} \cdot \mathrm{nm})$. Then the system was equilibrated for $100 \mathrm{ps}$ at a constant temperature of $300 \mathrm{~K}$ and a pressure of 1 bar using modified Berendsen thermostat. ${ }^{32}$ During the minimization and equilibration processes, FGs and ODs were constrained. Then, FGs and ODs were released, and MD simulations were performed. The equations of motion were integrated with a time step of 2 fs using the leap-frog algorithm ${ }^{33}$ and data were collected every 10 ps. NPT ensemble (constant number of atoms, constant pressure $\mathrm{P}=1 \mathrm{bar}$, and constant temperature $\mathrm{T}=$ 298.15 K) were employed in all simulations. In the course of production runs, the pressure was coupled to an isotropic Parrinello - Rahman barostat ${ }^{34}$ and the temperature was regulated using the Nose - Hoover thermostat ${ }^{35}$. For equilibration purposes, a Berendsen barostat ${ }^{36}$ was implemented to keep the system at constant pressure. Concentration of $\mathrm{Na}^{+}$cations were determined by $\mathrm{pH}$ conditions, and the excess negative charge was neutralized by $\mathrm{Na}^{+}$. During the dynamic simulation, trajectories of the systems were saved every 20 ps. VMD $^{37}$ program was employed for the visualization. 
(a)

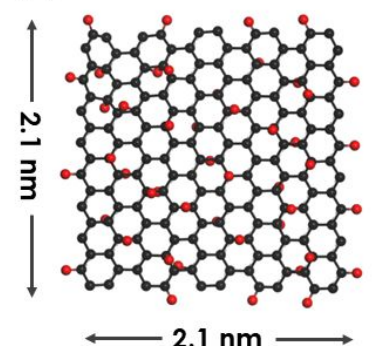

(d)

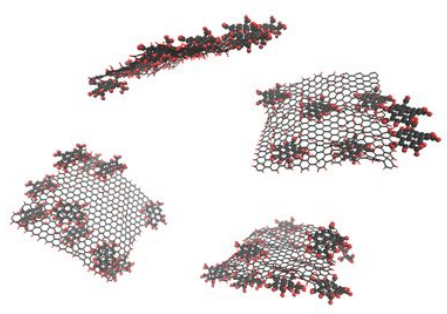

(b)

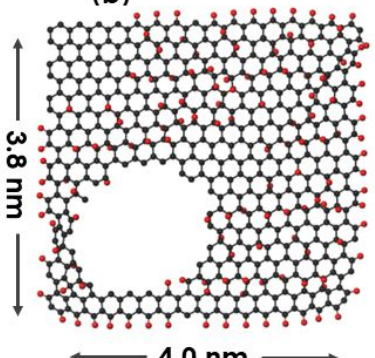

(e)

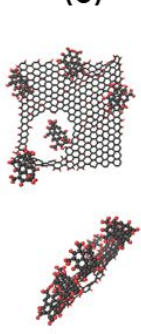

(c)
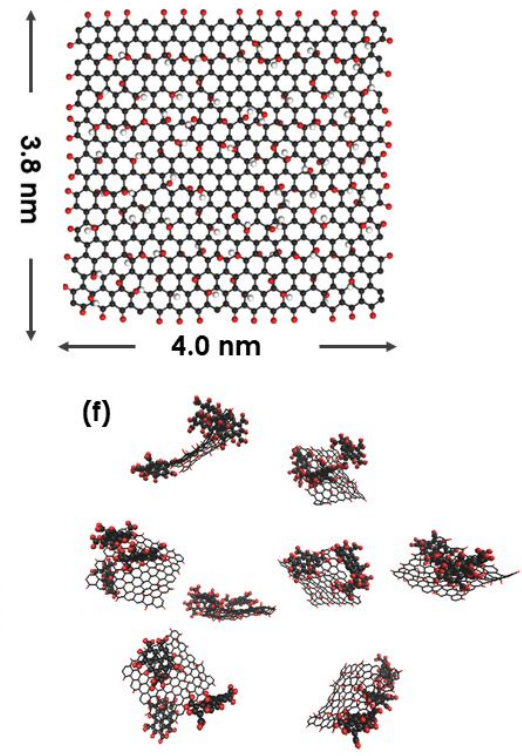

Figure S2. Setup of the simulation system. (a-c) Model of small sized FG, big sized FG with hole, and big sized FG. Initial system setup for the aggregation of big sized GO (d), big sized GO with hole (e), and small sized GO (f) at pH 12, pH 14 or pH 12 with $0.50 \mathrm{mM} \mathrm{Ca}^{2+}$. 

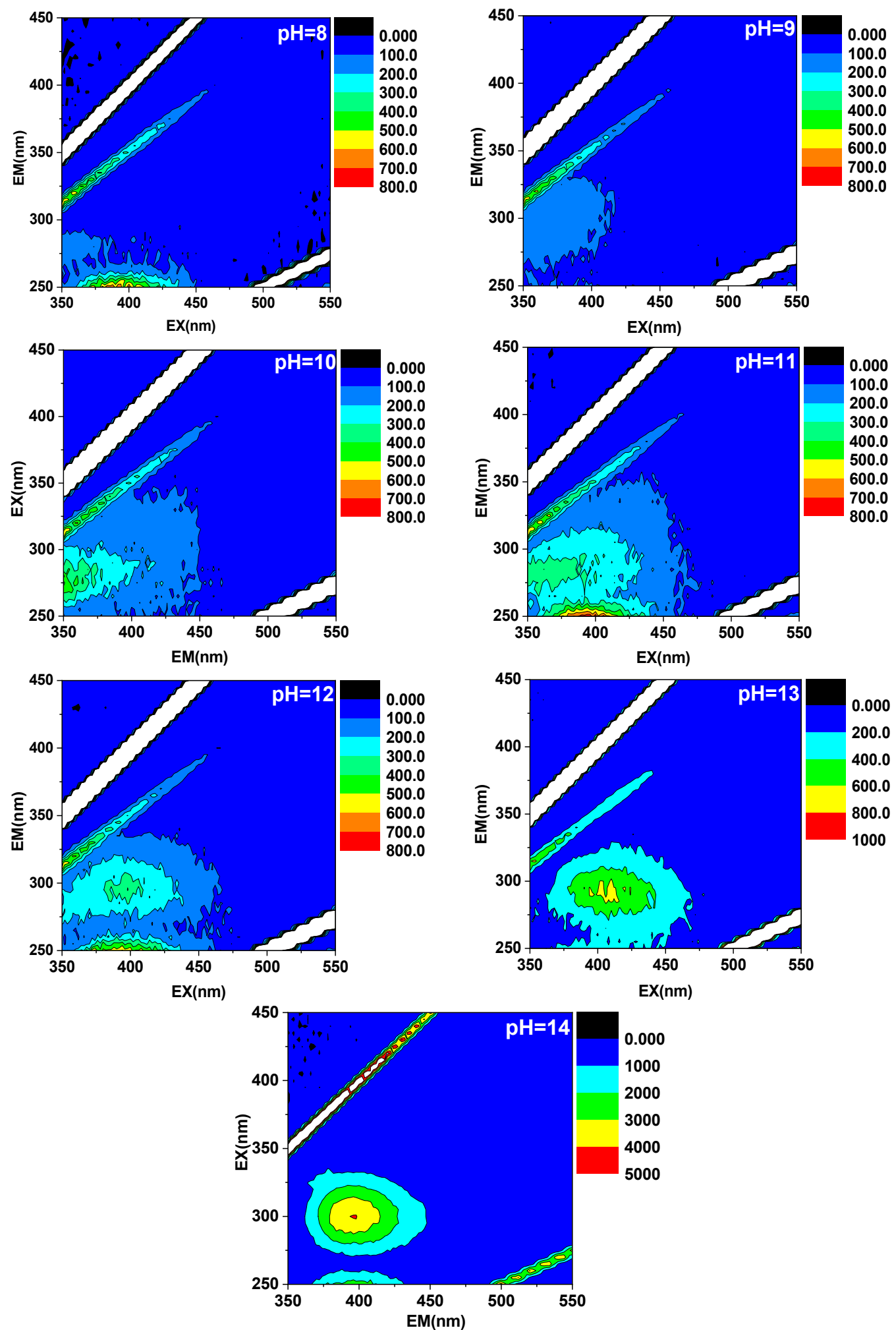

Figure S3. Fluorescence spectra of OD in water solution when $\mathrm{pH}$ was shifted between 8 and 14 . 

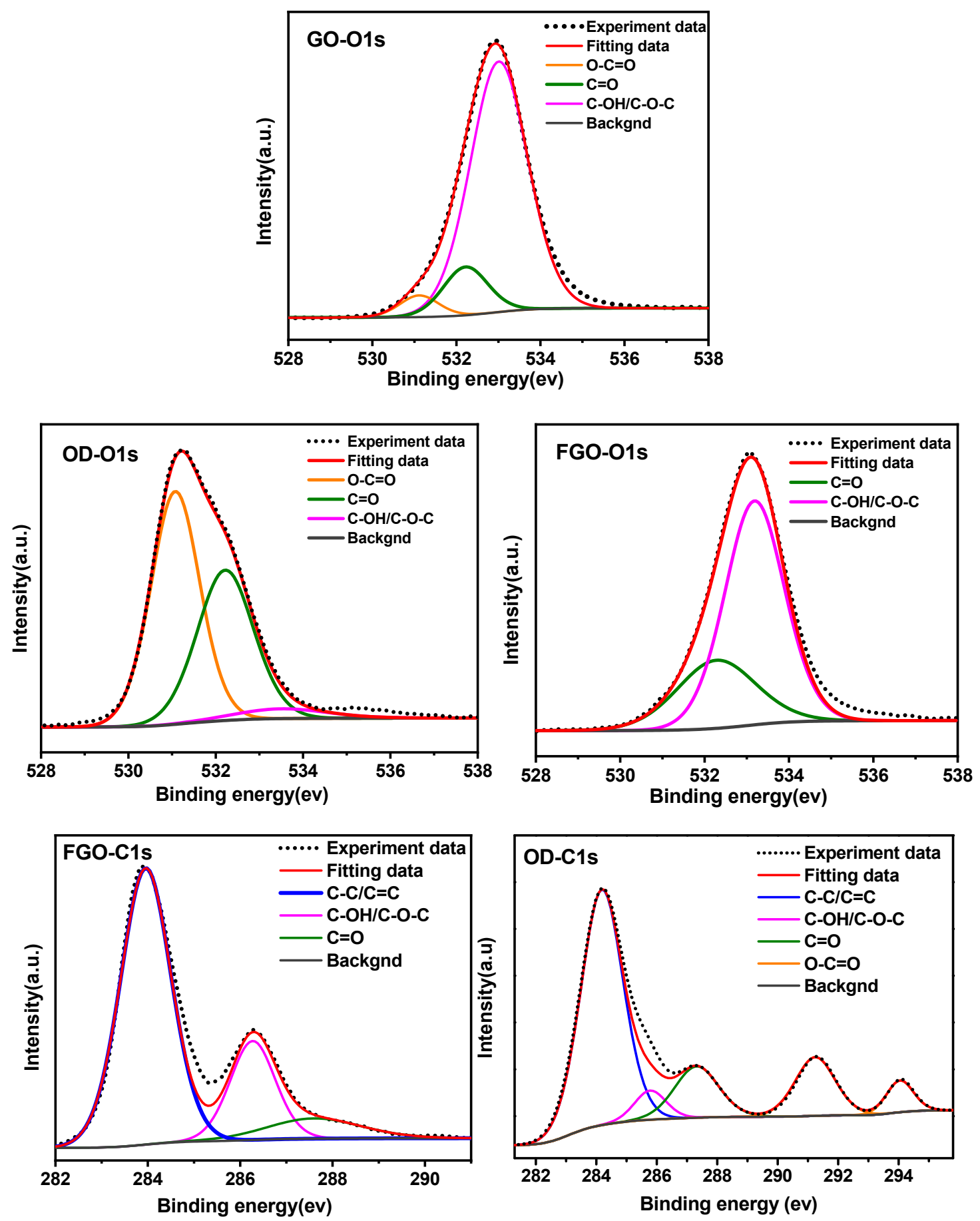

Figure S4. XPS spectra of GO, OD, and FG.

Table S4-1. XPS data of GO, OD, and FG (O1s).

\begin{tabular}{ccccc}
\hline Sample & $\mathrm{C}: \mathrm{O}$ & $\% \mathrm{C}-\mathrm{O} / \mathrm{C}-\mathrm{O}-\mathrm{C}$ & $\% \mathrm{C}=\mathrm{O}$ & $\% \mathrm{O}-\mathrm{C}=\mathrm{O}$ \\
\hline GO & 2.29 & 82.64 & 12.40 & 4.96 \\
OD & 1.59 & 5.11 & 38.07 & 56.82 \\
\hline
\end{tabular}




\begin{tabular}{lllll}
\hline FG & 3.60 & 71.43 & 28.57 & 0 \\
\hline
\end{tabular}

Table S4-2. XPS data of OD and FG (C1s).

\begin{tabular}{ccccc}
\hline Sample & $\% \mathrm{C}-\mathrm{C} / \mathrm{C}=\mathrm{C}$ & $\% \mathrm{C}-\mathrm{O} / \mathrm{C}-\mathrm{O}-\mathrm{C}$ & $\% \mathrm{C}=\mathrm{O}$ & $\% \mathrm{O}-\mathrm{C}=\mathrm{O}$ \\
\hline FG & 68.49 & 21.92 & 9.59 & 0 \\
OD & 59.4 & 3.8 & 14.5 & 22.3 \\
\hline
\end{tabular}

Based on the XPS results, molecular formula s of FG and OD were determined:

\section{Model of FG}

(i) molecular formula was set to be $\mathrm{C}_{\mathrm{a}}(\mathrm{C}-\mathrm{O}-\mathrm{C})_{\mathrm{b}}(\mathrm{C}=\mathrm{O})_{\mathrm{c}}(\mathrm{C}-\mathrm{OH})_{\mathrm{d}}$;

(ii) according to Table $\mathrm{S} 4-1, \mathrm{~b}+\mathrm{d} / \mathrm{c}=71.43 / 28.57=2.5$. According to Table $\mathrm{S} 4-2, \mathrm{~b}+\mathrm{d}=21$, because $\mathrm{b}+\mathrm{d} / \mathrm{c}=2.5$, so $\mathrm{c}=8.4 \approx 9$, and $\mathrm{a}=100-21-9=70$, so the molecular formula was $\mathrm{C}_{70}(\mathrm{C}-\mathrm{O}$ $\mathrm{C})_{\mathrm{b}}(\mathrm{C}=\mathrm{O})_{9}(\mathrm{C}-\mathrm{OH})_{\mathrm{d}}$;

(iii) according to Table S4-1, $\mathrm{C}: \mathrm{O}=3.6$, then we have $(70+2 b+9+d) /(b+9+d)=3.6$ and $b+d=21$, so $\mathrm{b}=8, \mathrm{~d}=13$;

Based on the above calculation, the molecular formula was determined to be $\mathrm{C}_{70}(\mathrm{C}-\mathrm{O}$ -

$\mathrm{C})_{8}(\mathrm{C}=\mathrm{O})_{9}(\mathrm{C}-\mathrm{OH})_{13}$.

\section{Model of OD}

(i) the content of $\mathrm{C}-\mathrm{O} / \mathrm{C}-\mathrm{O}-\mathrm{C}$ was low and was negligible, thus, molecular formula was set to be $\mathrm{C}_{\mathrm{a}}(\mathrm{C}=\mathrm{O})_{\mathrm{b}}(\mathrm{COOH})_{\mathrm{c}}$;

(ii) according to Table $\mathrm{S} 4-1, \mathrm{~b} / \mathrm{c}=38.07 / 56.82=0.67$. According to Table $\mathrm{S} 4-2, \mathrm{~b}=4$, because $\mathrm{b} / \mathrm{c}=0.67$, so $\mathrm{c}=6$, and the molecular formula was $\mathrm{C}_{\mathrm{a}}(\mathrm{C}=\mathrm{O})_{4}(\mathrm{COOH})_{6}$;

(iii) according to Table $\mathrm{S} 4-1, \mathrm{C}: \mathrm{O}=1.59$, so $(\mathrm{a}+4+6) /(4+12)=1.59$, and we get $\mathrm{a}=15.44 \approx 15$ Thus, the molecular formula of OD was determined to be $\mathrm{C}_{15}(\mathrm{C}=\mathrm{O})_{4}(\mathrm{COOH})_{6}$.

It should be noted that during the calculation, several approximations were made and there may be deviations between the real composition of FG (or OD) and this formula but would not have effect in exploring the microscopic aggregation properties.

The quantity of FG and OD was determined according to thermogravimetric analysis that OD made up roughly a third of the mass of GO. 

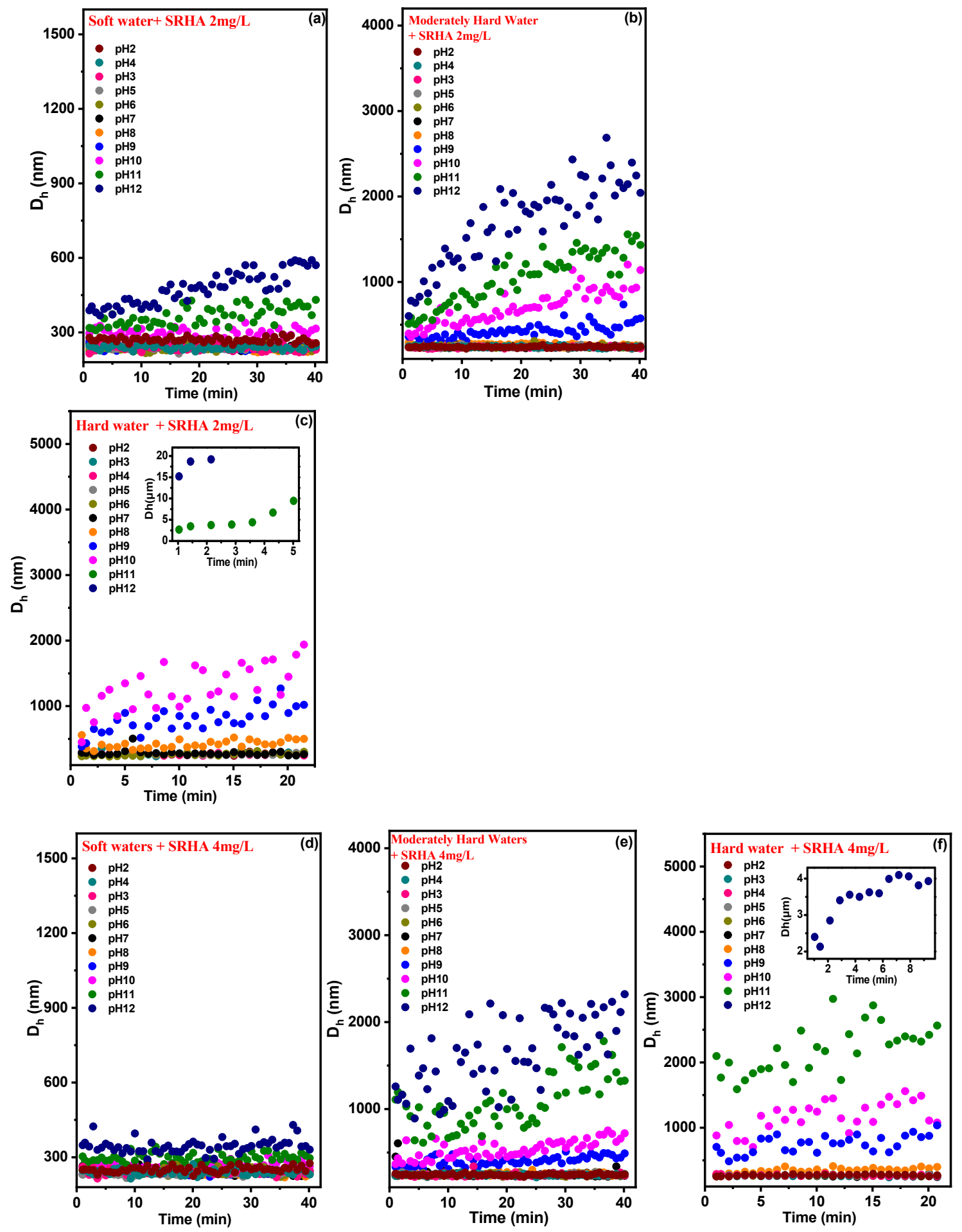

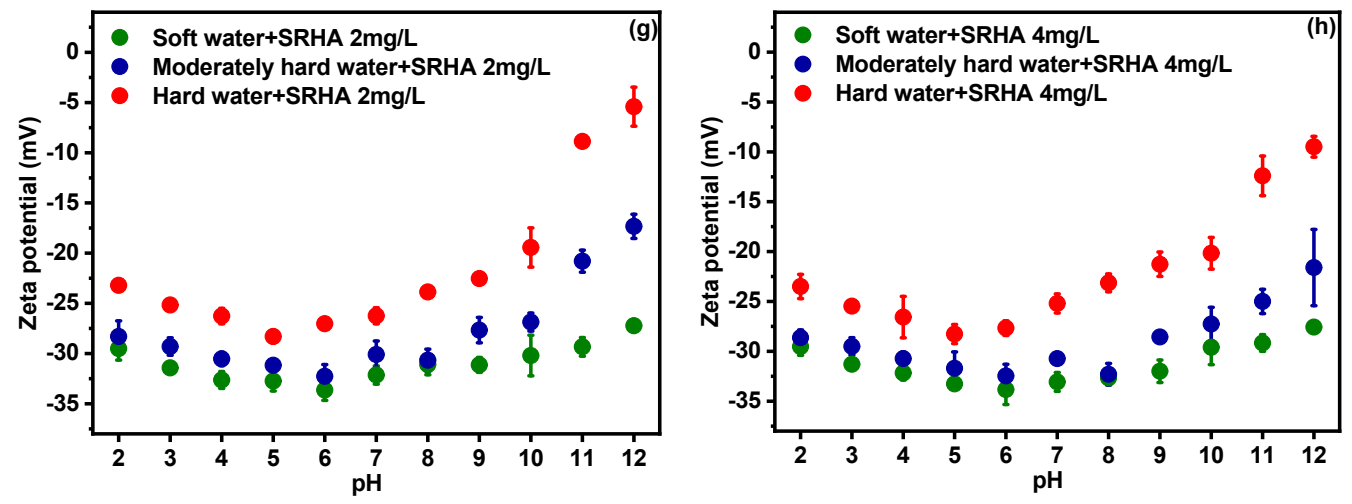

Figure S5. Hydrodynamic diameter $\left(\mathrm{D}_{\mathrm{h}}\right)$ changes of GO at pH 2 12 in soft (a), moderately hard (b), and hardwater (c) with the presence of $2 \mathrm{mg} / \mathrm{L}$ SRHA. $\mathrm{D}_{\mathrm{h}}$ changes of GO at pH 2 12 in soft (d), moderately hard (e), and hardwater (f) with the presence of $4 \mathrm{mg} / \mathrm{L} \mathrm{SRHA}$. (g) zeta potential of GO in soft, moderately hard, and hardwater with the presence of $2 \mathrm{mg} / \mathrm{L}$ SRHA. (h) zeta potential of GO in soft, moderately hard, and hardwater with the presence of $4 \mathrm{mg} / \mathrm{L}$ SRHA. 


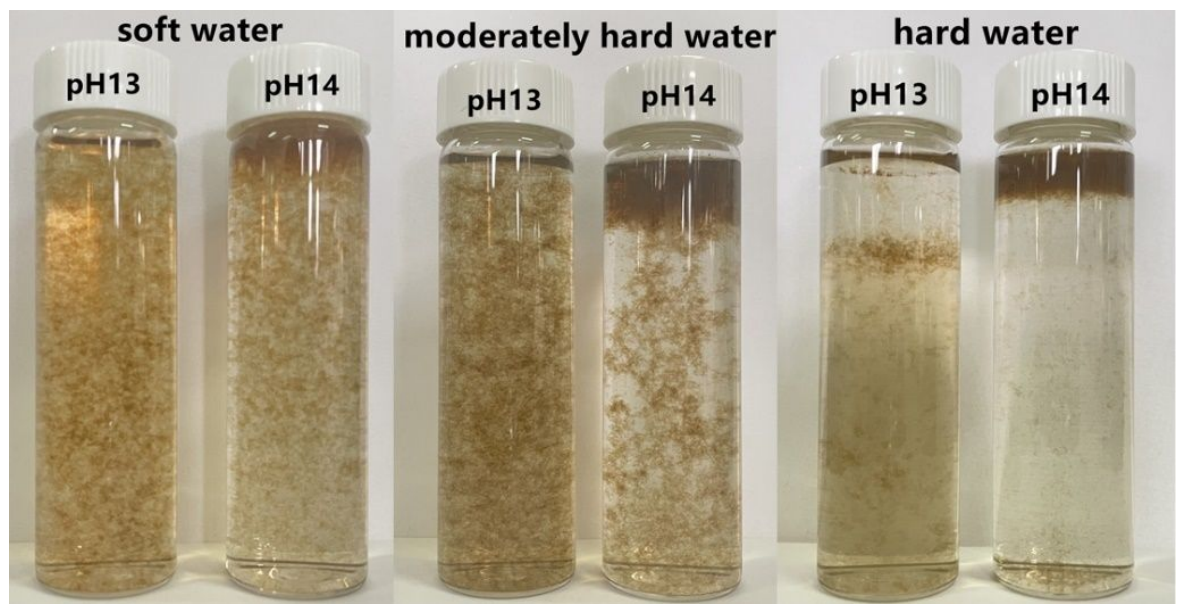

Figure S6. Aggregation of GO was observed immediately after the pH was adjusted to pH 13 and pH 14 . At $\mathrm{pH} 13$ and 14 (Figure S6), the aggregation was so significant that the diameter was hard to measure, and therefore, was not shown in Figure 3. 

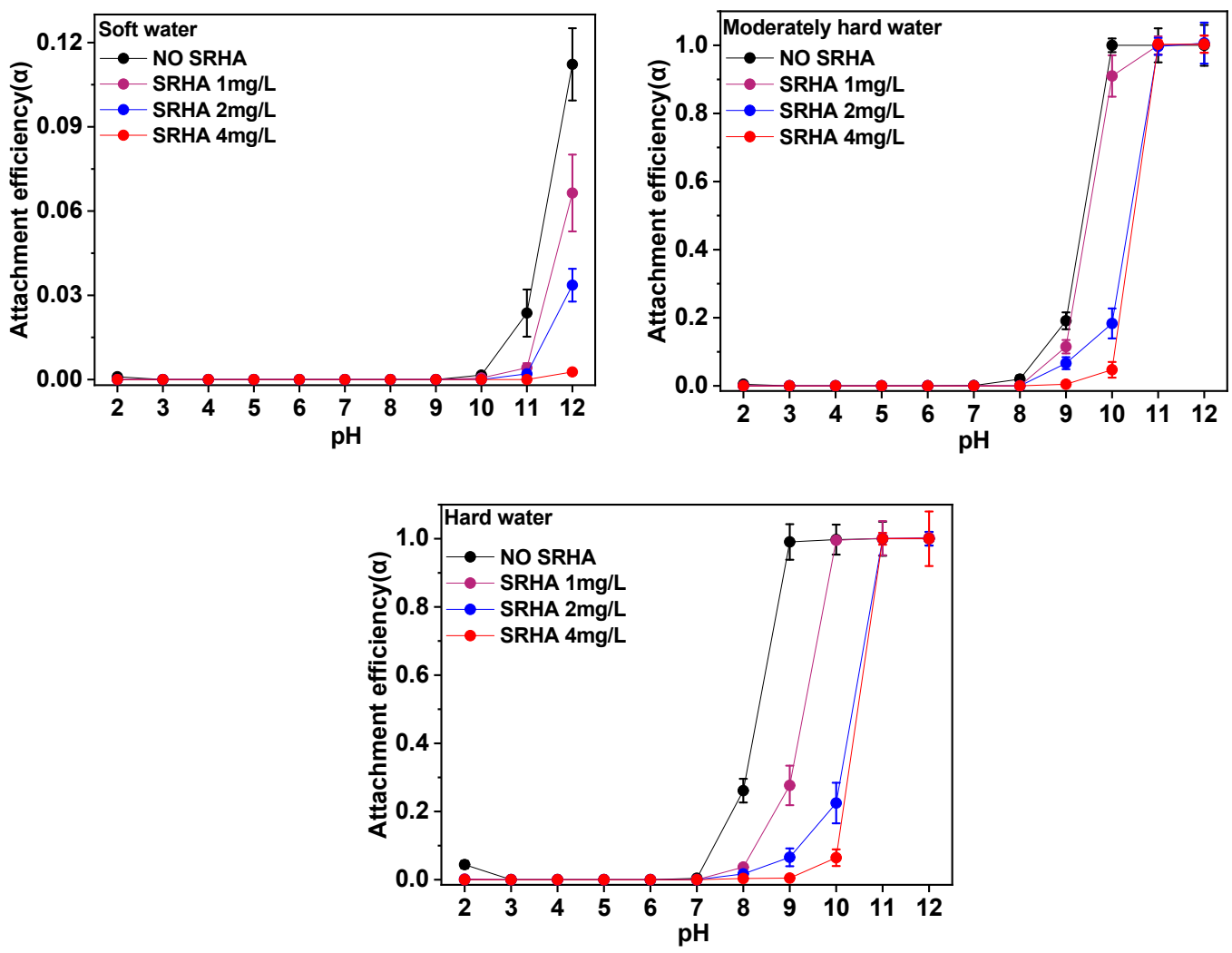

Figure S7. Attachment efficiencies $(\alpha)$ of GO as a function of $\mathrm{pH}$, the hardness of water, and the presence of NOM. 


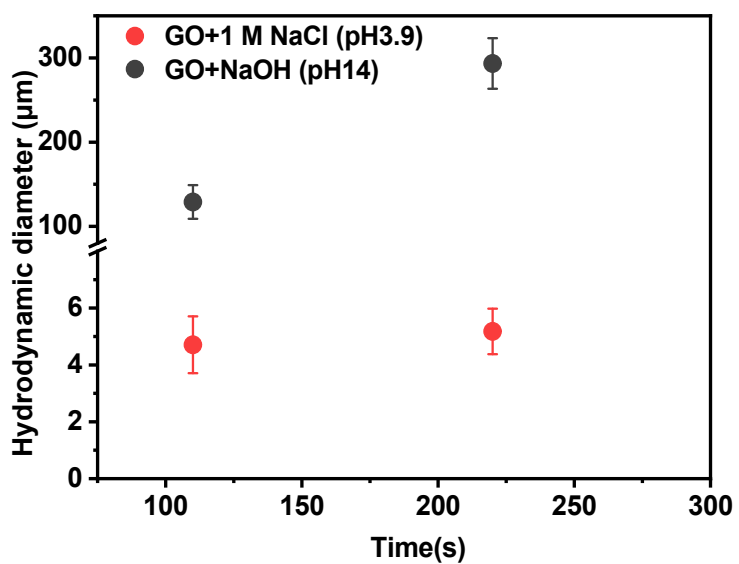

Figure S8. Hydrodynamic diameter changes when the $\mathrm{pH}$ was adjusted to $\mathrm{pH} 14$ or the addition of $1 \mathrm{M}$ $\mathrm{NaCl}$. 

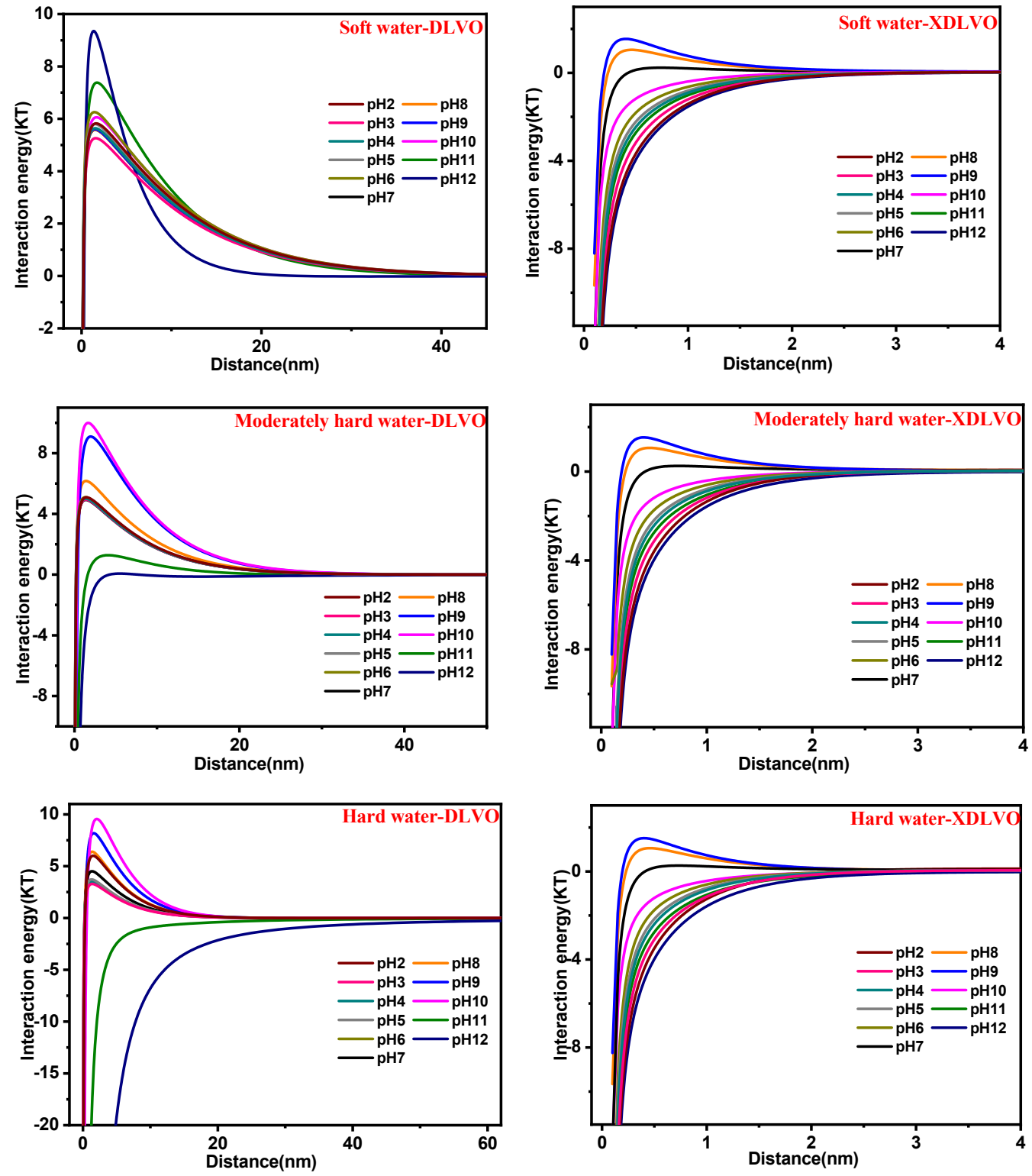

Figure S9. DLVO and XDLVO interaction profiles between GO sheets as a function of separation distance in different surface water. 
(a)
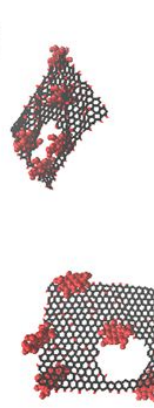

(d)
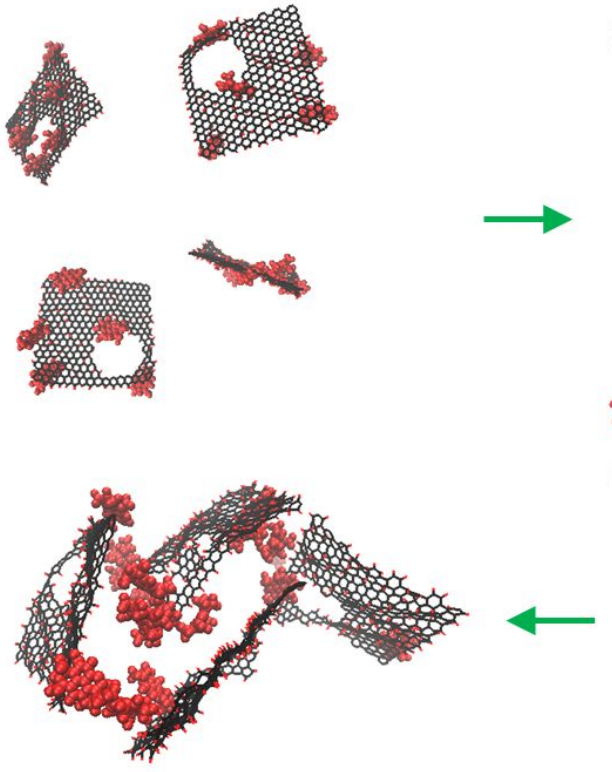

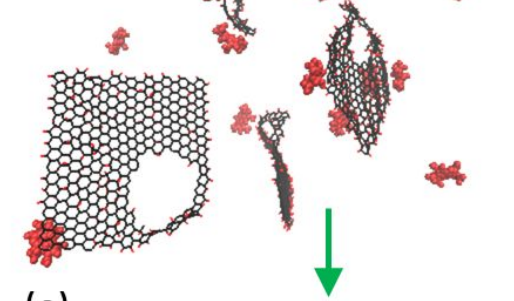

(c)

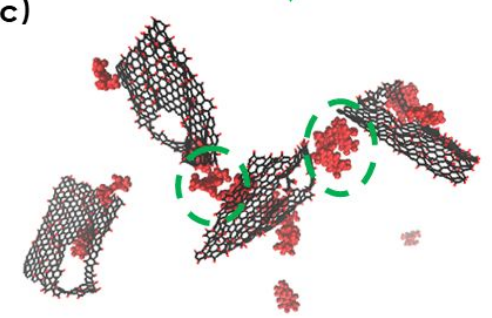

Figure S10. Representative trajectories during the aggregation of big sized GO with hole at $\mathrm{pH}$ 14. (a) Initial setup of GO aggregates. (b) Stripping of OD. (c) Recombination of ODs to FGs and the formation of FG-ODs aggregates. (d) Adjustment of the FG-ODs aggregates.

(a)
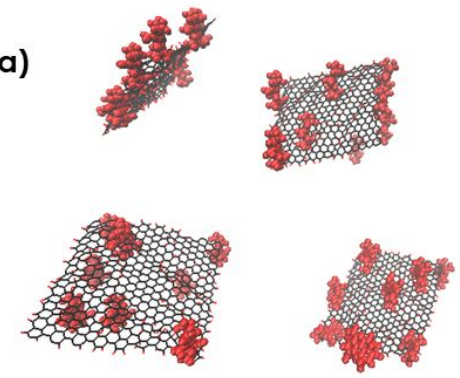

(d)

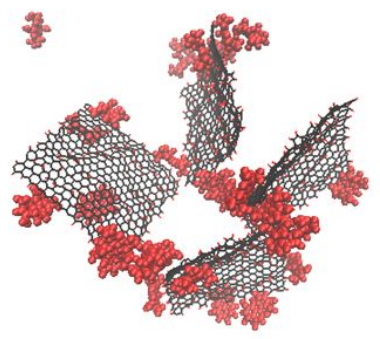

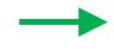

(c)
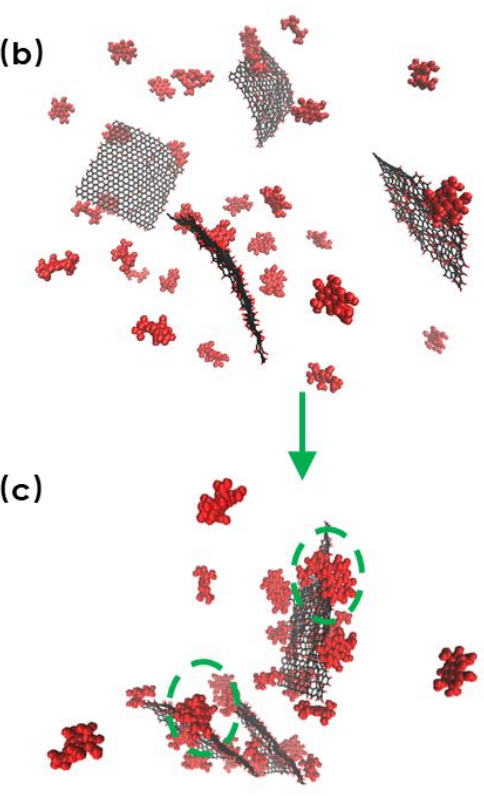

Figure S11. Representative trajectories during the aggregation of big sized GO at $\mathrm{pH} 14$. (a) Initial setup of GO aggregates. (b) Stripping of OD, recombination of ODs to FGs and the formation of FG-ODs aggregates. (d) Adjustment of the FG-ODs aggregates. 

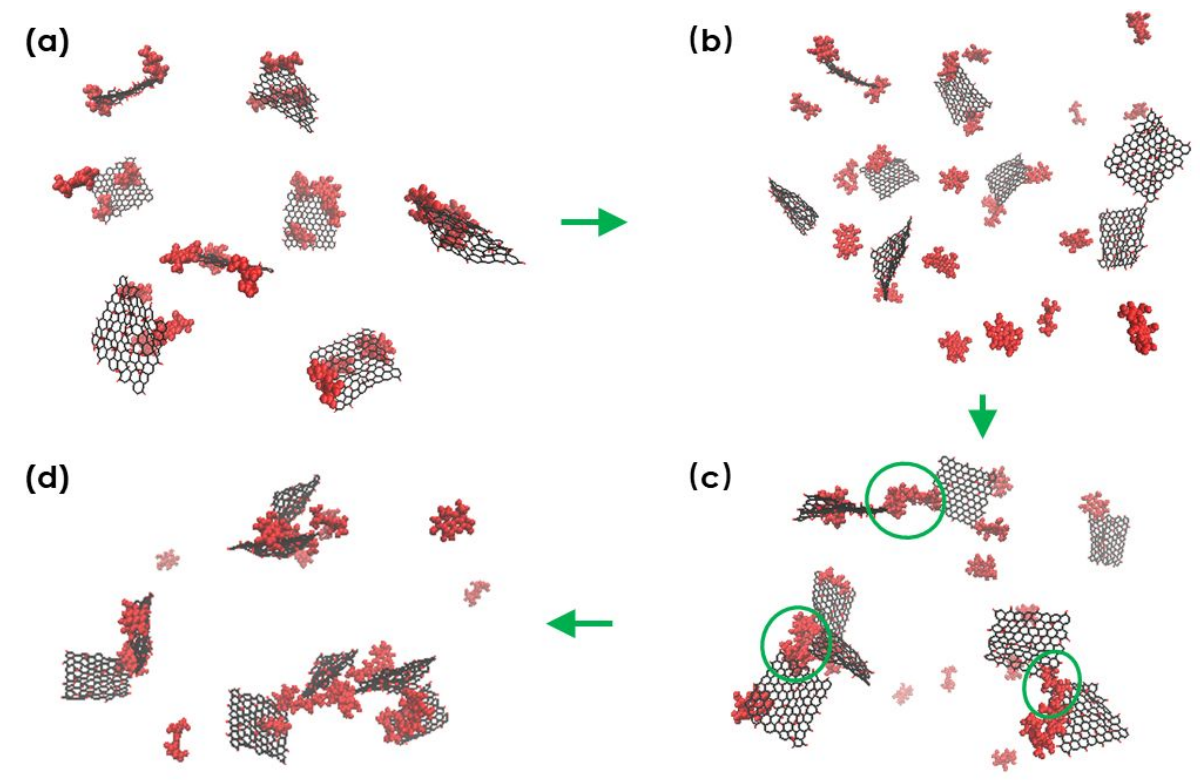

Figure S12. Representative trajectories during the aggregation of small sized GO at $\mathrm{pH} 12$ with $0.50 \mathrm{mM}$ $\mathrm{Ca}^{2+}$. (a) Initial setup of $\mathrm{GO}$ aggregates. (b) Stripping of OD, recombination of ODs to FGs and the formation of FG-ODs aggregates. (d) Adjustment of the FG-ODs aggregates.
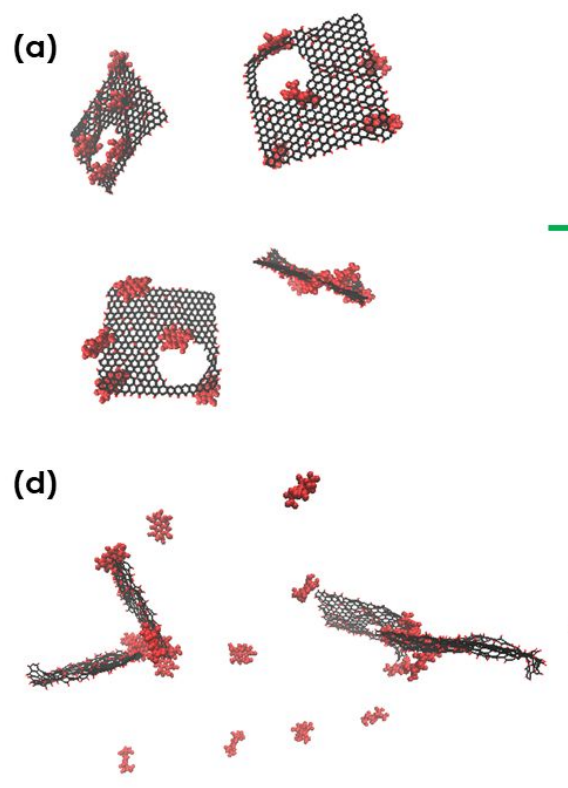

(b)

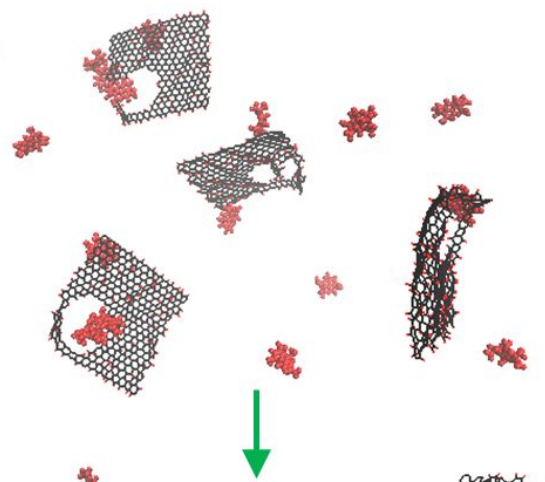

(c)

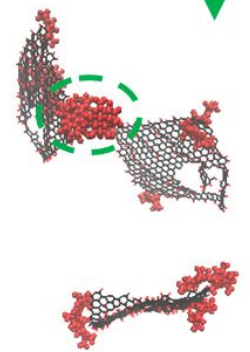

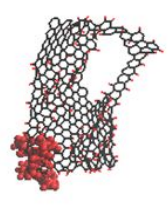

Figure S13. Representative trajectories during the aggregation of big sized GO with hole at $\mathrm{pH} 12$ with $0.50 \mathrm{mM} \mathrm{Ca}^{2+}$. (a) Initial setup of GO aggregates. (b) Stripping of OD, recombination of ODs to FGs and the formation of FG-ODs aggregates. (d) Adjustment of the FG-ODs aggregates. 
(a)
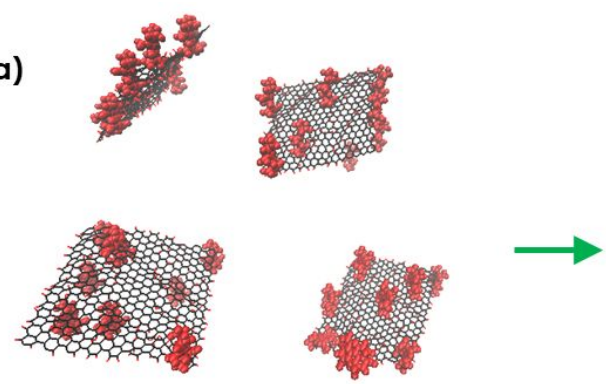

(d)

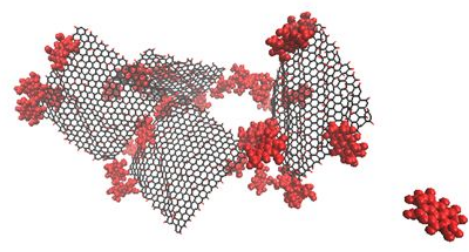

(b)

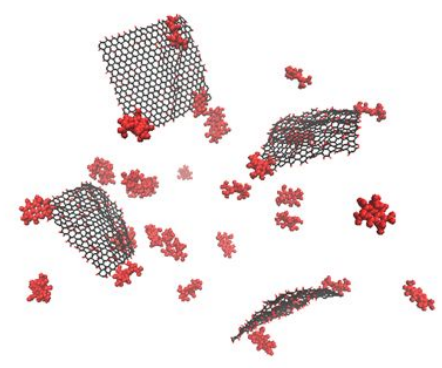

(c)

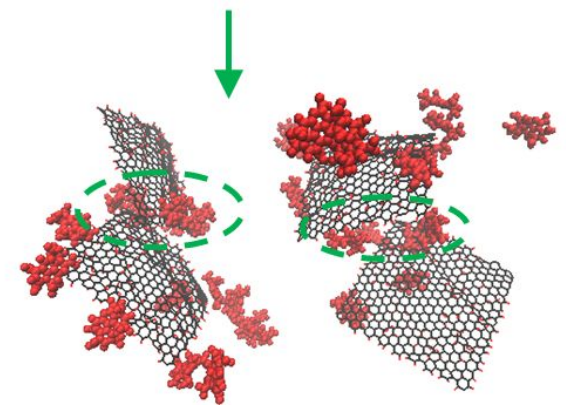

Figure S14. Representative trajectories during the aggregation of big sized GO at $\mathrm{pH} 12$ with $0.50 \mathrm{mM}$ $\mathrm{Ca}^{2+}$. (a) Initial setup of GO aggregates. (b) Stripping of OD, recombination of ODs to FGs and the formation of FG-ODs aggregates. (d) Adjustment of the FG-ODs aggregates. 
Table S5-1. Net charges on GO at $\mathrm{pH} 2 \sim 12$ in moderately water.

\begin{tabular}{cccccccc}
\hline $\mathrm{pH}$ & $\begin{array}{c}\Delta_{\mathrm{HCl}} \\
(\mathrm{mL})\end{array}$ & $\begin{array}{c}\text { Amount of } \\
\text { deprotonated groups } \\
\text { on GO (mmol/L) }\end{array}$ & $\begin{array}{c}\text { Negative } \\
\text { charges on } \mathrm{GO} \\
(\mathrm{mmol} / \mathrm{L})\end{array}$ & $\begin{array}{c}\text { Adsorbed } \\
\mathrm{Ca}^{2+} \\
(\mathrm{mmol} / \mathrm{L})\end{array}$ & $\begin{array}{c}\text { Adsorbed } \\
\mathrm{Mg}^{2+} \\
(\mathrm{mmol} / \mathrm{L})\end{array}$ & $\begin{array}{c}\text { Total positive } \\
\text { charges } \\
(\mathrm{mmol} / \mathrm{L})\end{array}$ & $\begin{array}{c}\text { Net charges } \\
(\mathrm{mmol} / \mathrm{L})\end{array}$ \\
\hline 12 & 8.76 & 0.8760 & -0.8760 & 0.2150 & 0.2179 & 0.8657 & -0.0103 \\
11 & 7.98 & 0.7980 & -0.7980 & 0.2050 & 0.1758 & 0.7614 & -0.0366 \\
10 & 7.07 & 0.7070 & -0.7070 & 0.1919 & 0.1276 & 0.6389 & -0.0681 \\
9 & 5.91 & 0.5910 & -0.5910 & 0.1492 & 0.0984 & 0.4952 & -0.0958 \\
8 & 5.69 & 0.5690 & -0.5690 & 0.0975 & 0.0687 & 0.3322 & -0.2368 \\
7 & 5.52 & 0.5520 & -0.5520 & 0.0687 & 0.0584 & 0.2541 & -0.2979 \\
6 & 4.95 & 0.4950 & -0.4950 & 0.0542 & 0.0503 & 0.2090 & -0.2860 \\
5 & 4.49 & 0.4490 & -0.4490 & 0.0531 & 0.0501 & 0.2064 & -0.2426 \\
4 & 4.35 & 0.4350 & -0.4350 & 0.0487 & 0.0499 & 0.1972 & -0.2378 \\
3 & 4.22 & 0.4220 & -0.4220 & 0.0462 & 0.0487 & 0.1898 & -0.2322 \\
\hline 2 & 4.10 & 0.4100 & -0.4100 & 0.0443 & 0.0479 & 0.1844 & -0.2256 \\
\hline
\end{tabular}

Table S5-2. Net charges on GO at $\mathrm{pH} 2 \sim 12$ in hard water.

\begin{tabular}{cccccccc}
\hline $\mathrm{pH}$ & $\begin{array}{c}\Delta_{\mathrm{HCl}} \\
(\mathrm{mL})\end{array}$ & $\begin{array}{c}\text { Amount of } \\
\text { deprotonated groups } \\
\text { on GO (mmol/L) }\end{array}$ & $\begin{array}{c}\text { Negative } \\
\text { charges on GO } \\
(\mathrm{mmol} / \mathrm{L})\end{array}$ & $\begin{array}{c}\text { Adsorbed } \\
\mathrm{Ca}^{2+} \\
(\mathrm{mmol} / \mathrm{L})\end{array}$ & $\begin{array}{c}\text { Adsorbed } \\
\mathrm{Mg}^{2+} \\
(\mathrm{mmol} / \mathrm{L})\end{array}$ & $\begin{array}{c}\text { Total positive } \\
\text { charges } \\
(\mathrm{mmol} / \mathrm{L})\end{array}$ & $\begin{array}{c}\text { Net charges } \\
(\mathrm{mmol} / \mathrm{L})\end{array}$ \\
\hline 12 & 8.76 & 0.8760 & -0.8760 & 0.3465 & 0.6127 & 1.9182 & 1.0422 \\
11 & 7.98 & 0.7980 & -0.7980 & 0.2089 & 0.1901 & 0.7978 & -0.0002 \\
10 & 7.07 & 0.7070 & -0.7070 & 0.1656 & 0.1828 & 0.6966 & -0.0104 \\
9 & 5.91 & 0.5910 & -0.5910 & 0.1394 & 0.1262 & 0.5310 & -0.0600 \\
8 & 5.69 & 0.5690 & -0.5690 & 0.0637 & 0.1109 & 0.3492 & -0.2198 \\
7 & 5.52 & 0.5520 & -0.5520 & 0.0613 & 0.1041 & 0.3308 & -0.2212 \\
6 & 4.95 & 0.4950 & -0.4950 & 0.0502 & 0.0844 & 0.2692 & -0.2258 \\
5 & 4.49 & 0.4490 & -0.4490 & 0.0421 & 0.0708 & 0.2258 & -0.2232 \\
4 & 4.35 & 0.4350 & -0.4350 & 0.0419 & 0.0704 & 0.2246 & -0.2104 \\
3 & 4.22 & 0.4220 & -0.4220 & 0.0401 & 0.0679 & 0.2160 & -0.2060 \\
\hline 2 & 4.10 & 0.4100 & -0.4100 & 0.0396 & 0.0672 & 0.2136 & -0.1964 \\
\hline
\end{tabular}



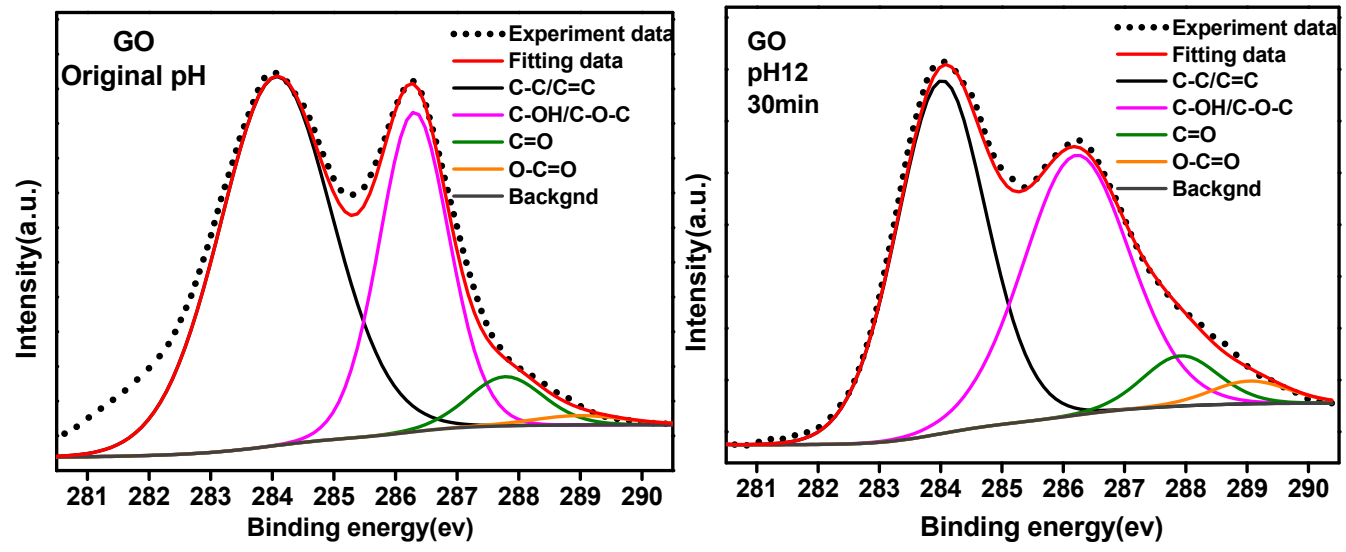

Figure S15. XPS spectra of GO, OD, and FG.

Table S6. XPS data of GO

\begin{tabular}{cccccc}
\hline Sample & $\mathrm{C}: \mathrm{O}$ & $\% \mathrm{C}-\mathrm{C} / \mathrm{C}=\mathrm{C}$ & $\% \mathrm{C}-\mathrm{O} / \mathrm{C}-\mathrm{O}-\mathrm{C}$ & $\% \mathrm{C}=\mathrm{O}$ & $\% \mathrm{O}-\mathrm{C}=\mathrm{O}$ \\
\hline GO-original pH (4.5 \pm 0.1$)$ & 2.29 & 59.44 & 33.27 & 5.30 & 1.99 \\
GO-pH12 (30min) & 2.30 & 51.54 & 38.14 & 7.22 & 3.10 \\
\hline
\end{tabular}




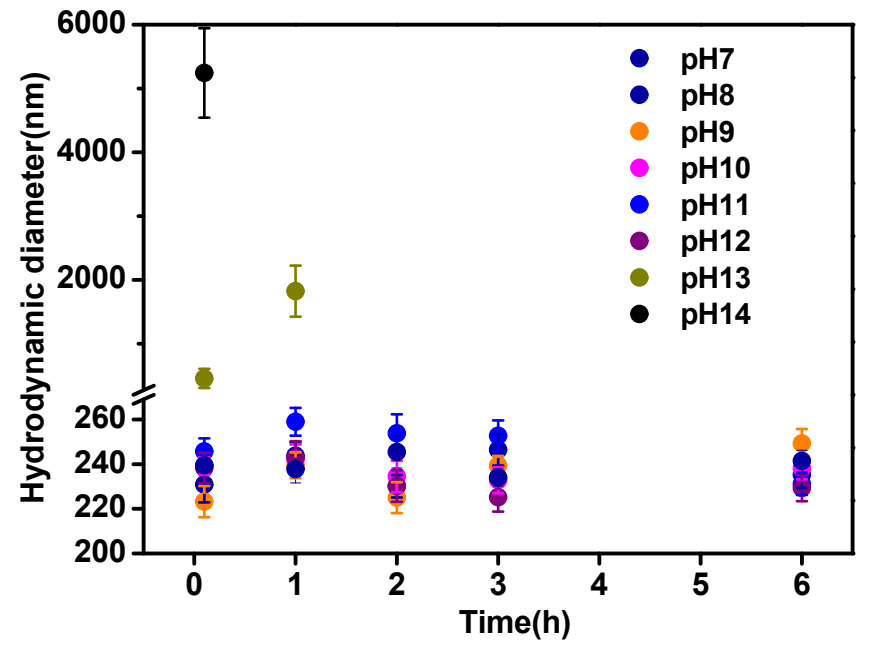

Figure S16. Hydrodynamic diameter changes as the $\mathrm{pH}$ were increased to $7 \sim 14$ with no ionic strength.

(Original $\mathrm{pH}$ value is 4.2 and original hydrodynamic diameter is $236.37 \mathrm{~nm}$ )

(a)

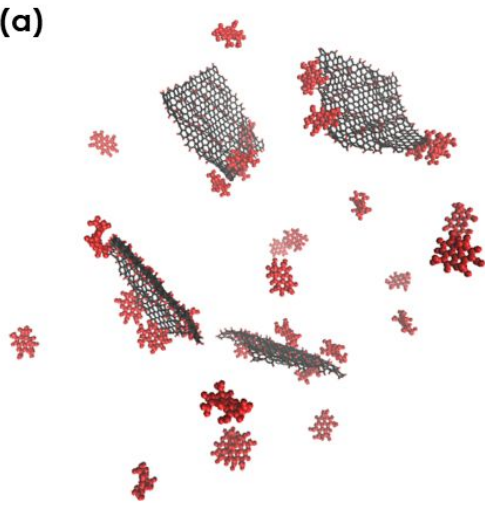

(b)

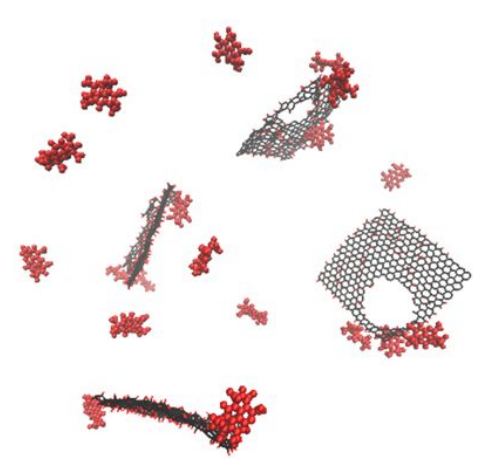

(c)

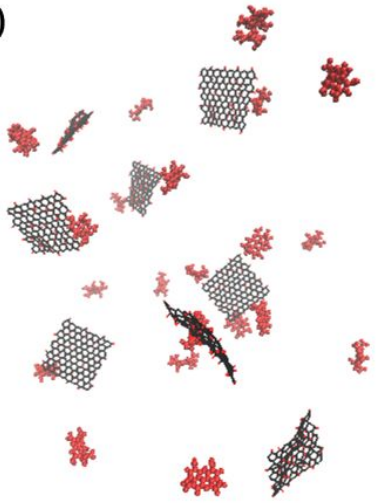

Figure S17. MD results for the aggregation of big sized GO (a), (b) big sized GO with hole, and small sized $\mathrm{GO}(\mathrm{c})$ at $\mathrm{pH} 12$. 

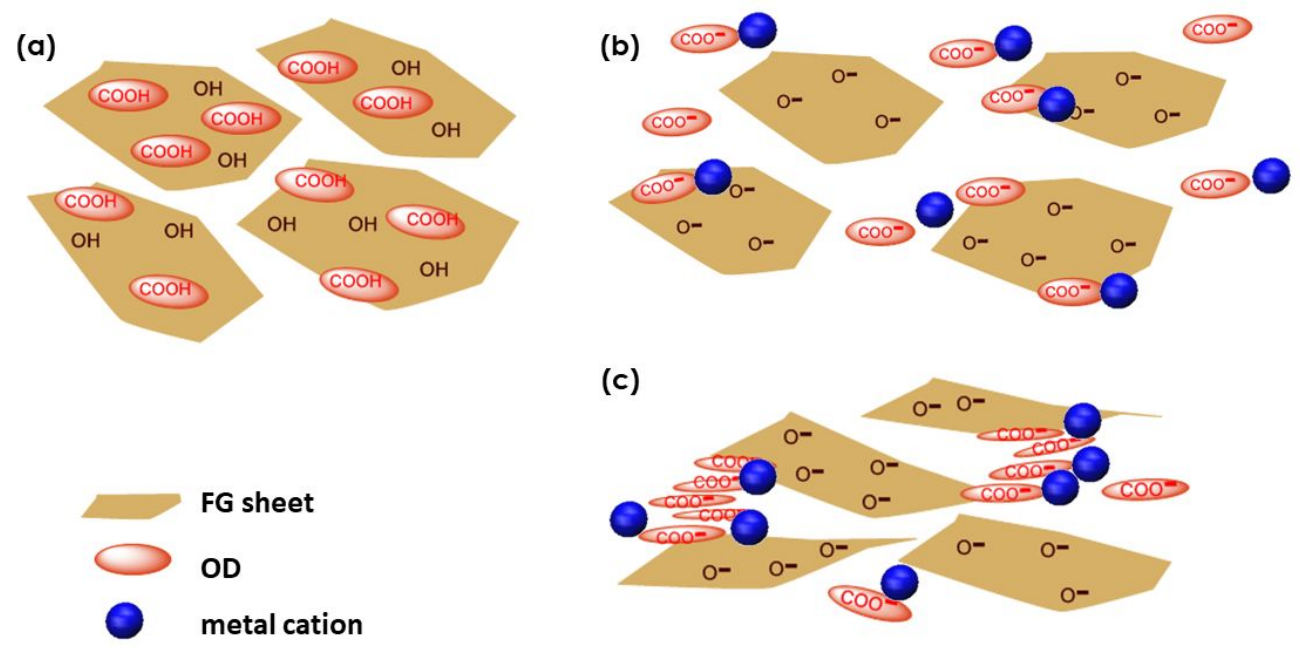

Figure S18. Mechanism of the promoted aggregation as $\mathrm{pH}$ increased. (a) Structural model of GO: GO consist of $\mathrm{OD}$ and $\mathrm{FG}(\mathrm{GO}=\mathrm{FG}+\mathrm{OD})$, almost all the hydroxy groups $(\mathrm{OH})$ were located on $\mathrm{FG}$, and carboxyl groups (COOH) were on OD. (b) Deprotonation of $\mathrm{OH}$ and $\mathrm{COOH}$ at $\mathrm{pH}>10$, stripping of $\mathrm{OD}$ due to electrostatic repulsions, and metal cations adsorption on OD and FG. (c) Aggregation of FG sheets and the formation of FG-OD aggregates. 


\section{References}

1. Short-Term Methods for Estimating the Chronic Toxicity of Effluents and Receiving Waters to Freshwater Organisms. EPA/600/4-89/001. 1994.

2. Wu, L.; Liu, L.; Gao, B.; Muñoz-Carpena, R.; Zhang, M.; Chen, H.; Zhou, Z.; Wang, H., Aggregation kinetics of graphene oxides in aqueous solutions: experiments, mechanisms, and modeling. Langmuir 2013, 29, (49), 15174-15181.

3. Chowdhury, I.; Duch, M. C.; Mansukhani, N. D.; Hersam, M. C.; Bouchard, D., Colloidal properties and stability of graphene oxide nanomaterials in the aquatic environment. Environmental Science \& Technology 2013, 47, (12), 6288-6296.

4. Dong; Lini; Ma; Danyang; Zhu; Liande; Zhou; Ming, The influence of oxidation debris containing in graphene oxide on the adsorption and electrochemical properties of 1,10phenanthroline-5,6-dione. The Analyst: The Analytical Journal of the Royal Society of Chemistry: A Monthly International Publication Dealing with All Branches of Analytical Chemistry 2016.

5. Rourke, J. P.; Pandey, P. A.; Moore, J. J.; Bates, M.; Kinloch, I. A.; Young, R. J.; Wilson, N. R., The Real Graphene Oxide Revealed: Stripping the Oxidative Debris from the Graphene-like Sheets. Angew Chem Int Ed Engl 2011, 50, (14), 3173-3177.

6. Guo, Z.; Wang, S.; Wang, G.; Niu, Z.; Yang, J.; Wu, W., Effect of oxidation debris on spectroscopic and macroscopic properties of graphene oxide. Carbon 2014, 76, 203-211.

7. Thomas, H. R.; Vallés, C.; Young, R. J.; Kinloch, I. A.; Wilson, N. R.; Rourke, J. P., Identifying the fluorescence of graphene oxide. Journal of Materials Chemistry C 2013, 1.

8. Konkena, B.; Vasudevan, S., Understanding Aqueous Dispersibility of Graphene Oxide and Reduced Graphene Oxide through pKa Measurements. The Journal of Physical Chemistry Letters 2012, 3, (7), 867-872.

9. Masliyah, J., Particle Deposition and Aggregation: Measurement, Modelling and Simulation. M. Elimelech et al. Journal of Colloid \& Interface Science 1998, 200, (1), 195-195.

10. Feriancikova, L.; Xu, S., Deposition and remobilization of graphene oxide within saturated sand packs. Journal of Hazardous Materials 2012, 235-236, (2), 194-200.

11. Hong, Y.; Honda, R. I.; Myung, N. V.; Walker, S. L., Transport of Iron-Based Nanoparticles: Role of Magnetic Properties. Environmental Science \& Technology 2009, 43, (23), 8834-9.

12. Chrysikopoulos, C. V.; Syngouna, V. I., Attachment of bacteriophages MS2 and ФX174 onto kaolinite and montmorillonite: Extended-DLVO interactions. Colloids and Surfaces B: Biointerfaces 2012, 92, 74-83.

13. Van Oss, C.; Giese, R.; Costanzo, P. M., DLVO and non-DLVO interactions in hectorite. Clays Clay Miner 1990, 38, (2), 151-159.

14. Brant, J. A.; Childress, A. E., Assessing short-range membrane-colloid interactions using surface energetics. J Membrane Sci 2002, 203, (1), 257-273.

15. Feriancikova, L.; Xu, S., Deposition and remobilization of graphene oxide within saturated sand packs. J Hazard Mater 2012, 235, 194-200.

16. Chia, T. W. R.; Nguyen, V. T.; McMeekin, T.; Fegan, N.; Dykes, G. A., Stochasticity of bacterial attachment and its predictability by the extended Derjaguin-Landau-Verwey-Overbeek theory. Appl Environ Microb 2011, 77, (11), 3757-3764.

17. Shao, W.; Liu, H.; Liu, X.; Wang, S.; Zhang, R., Anti-bacterial performances and biocompatibility of bacterial cellulose/graphene oxide composites. RSC Advances 2015, 5, (7), 4795-4803.

18. Golden, T. D.; Shumsky, M. G.; Zhou, Y.; VanderWerf, R. A.; Van Leeuwen, R. A.; Switzer, J. A., Electrochemical deposition of copper (I) oxide films. Chem Mater 1996, 8, (10), 2499-2504. 
19. Oldfield, G.; Ung, T.; Mulvaney, P., Au@ SnO2 core-shell nanocapacitors. Adv Mater 2000, 12, (20), 1519-1522.

20. Campanari, S., Thermodynamic model and parametric analysis of a tubular SOFC module. J Power Sources 2001, 92, (1), 26-34.

21. Park; Jeong-Ann; Kim; Song-Bae, DLVO and XDLVO calculations for bacteriophage MS2 adhesion to iron oxide particles. Journal of contaminant hydrology 2015.

22. Van Oss, C., Acid-base interfacial interactions in aqueous media. Colloids and Surfaces A: Physicochemical and Engineering Aspects 1993, 78, 1-49.

23. Ong, Y.-L.; Razatos, A.; Georgiou, G.; Sharma, M. M., Adhesion Forces between E. c oli bacteria and biomaterial surfaces. Langmuir 1999, 15, (8), 2719-2725.

24. Yang, J.; Chen, J.; Song, J., Studies of the surface wettability and hydrothermal stability of methyl-modified silica films by FT-IR and Raman spectra. Vib Spectrosc 2009, 50, (2), 178-184. 25. Jorgensen, W. L.; Maxwell, D. S.; Tirado-Rives, J., Development and testing of the OPLS all-atom force field on conformational energetics and properties of organic liquids. J Am Chem Soc 1996, 118, (45), 11225-11236.

26. Van Der Spoel, D.; Lindahl, E.; Hess, B.; Groenhof, G.; Mark, A. E.; Berendsen, H. J., GROMACS: fast, flexible, and free. J Comput Chem 2005, 26, (16), 1701-1718.

27. Darden, T.; York, D.; Pedersen, L., Particle mesh Ewald: An N · log (N) method for Ewald sums in large systems. The Journal of chemical physics 1993, 98, (12), 10089-10092.

28. Berendsen, H.; Grigera, J.; Straatsma, T., The missing term in effective pair potentials. Journal of Physical Chemistry 1987, 91, (24), 6269-6271.

29. Jian, C.; Zeng, H.; Liu, Q.; Tang, T., Probing the Adsorption of Polycyclic Aromatic Compounds onto Water Droplets Using Molecular Dynamics Simulations. J Phys Chem C 2016, 120, (26), 14170-14179.

30. Hess, B.; Bekker, H.; Berendsen, H. J.; Fraaije, J. G., LINCS: a linear constraint solver for molecular simulations. J Comput Chem 1997, 18, (12), 1463-1472.

31. SETTLE, M. S. K. P., An analytical version of the SHAKE and RATTLE algorithm for rigid water molecules. J. Comput. Chem 1992, 13, 952-962.

32. Lemak, A.; Balabaev, N., On the Berendsen thermostat. Mol Simulat 1994, 13, (3), 177-

187.

33. Lerf, A.; He, H.; Forster, M.; Klinowski, J., Structure of graphite oxide revisited. The Journal of Physical Chemistry B 1998, 102, (23), 4477-4482.

34. Parrinello, M.; Rahman, A., Polymorphic transitions in single crystals: A new molecular dynamics method. Journal of Applied physics 1981, 52, (12), 7182-7190.

35. Lysenko, W. Equilibrium phase-space distributions; 1978.

36. Berendsen, H. J.; Postma, J. v.; van Gunsteren, W. F.; DiNola, A.; Haak, J., Molecular dynamics with coupling to an external bath. The Journal of chemical physics 1984, 81, (8), 36843690.

37. Humphrey, W.; Dalke, A.; Schulten, K., VMD: visual molecular dynamics. Journal of molecular graphics 1996, 14, (1), 33-38. 